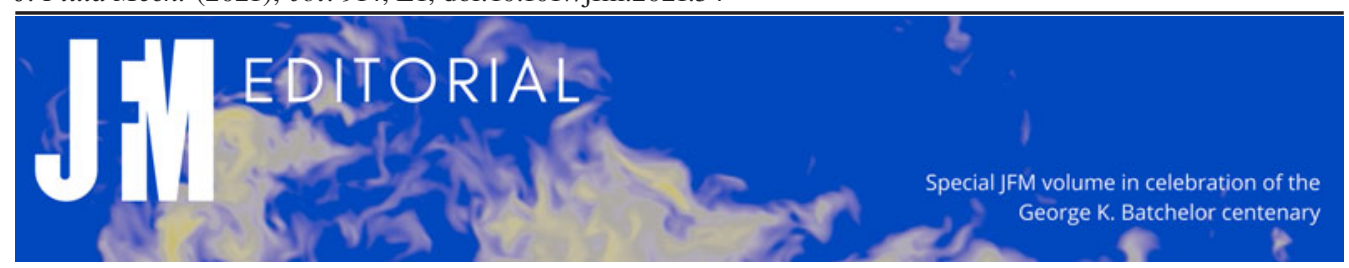

\title{
Celebrating George K. Batchelor's Centenary
}

This special issue of the Journal of Fluid Mechanics celebrates the centenary of the birth of Professor George Batchelor FRS, the Founding Editor of the Journal. The issue was initially designed to follow a Symposium to mark the centenary that was to have been held in Cambridge in March 2020, to which all the speakers were invited by the Symposium Scientific Committee. Unfortunately, as a result of the Covid-19 pandemic the meeting was postponed until March 2021 and, given the circumstances at the time of writing, will now be a 'virtual meeting'.

George, as he was known to friends and colleagues, was a towering internationally renowned figure in fluid mechanics, who, in addition to founding JFM in 1956 at the early age of 36, also established the Department of Applied Mathematics and Theoretical Physics at the University of Cambridge in 1959, which was initially the home of JFM. Now the current editorial board of 37 members spans the globe.

George served as the Editor-in-Chief, alone initially, and then alongside Professor Keith Moffatt FRS until 1983, and during his tenure of almost 30 years established the standards that have made JFM the foremost journal in fluid mechanics in the world. As I am sure is the case for contributors to the Journal, as a young researcher I considered it a major achievement to publish my work there and I still get a thrill when I get notification of acceptance from an Associate Editor. George's ethos about what papers should contain and how referees should review submissions pervades our practices today and has served our community extremely well.

George was also very involved with the international promotion of fluid mechanics. As described in Patrick Huerre's article, he was the co-founder of the European Mechanics Society, now the thriving organisation EUROMECH. He was also involved in the International Union of Theoretical and Applied Mechanics.

When I arrived in Cambridge as a PhD student in 1969 George was at the height of his powers. Cambridge University Press had recently published his seminal textbook An Introduction to Fluid Mechanics, which remains the book to read. Around this time he also shifted his research interests from turbulence, which had occupied him since he arrived in Cambridge in 1945 to work with G. I. Taylor, and was beginning his work on low Reynolds number flows and suspensions. Many of the papers in this issue deal with these topics and refer to his research as inspirations for the topics studied.

As a PhD student, postdoc and in my first years on the faculty in DAMTP, I was amazed and impressed by George's approachability and care for what we now call early career researchers (ECRs). He found time to provide advice and encouragement, and led by example: for example, by making his attendance at the weekly Friday afternoon seminars 


\section{P.F. Linden}

a priority. In keeping with this, many of the papers in this issue are from ECRs invited to submit a paper after selection by the Symposium Scientific Committee. I should add, however, that as George would have insisted, all the papers were refereed in the usual manner.

In keeping with George's concerns about the international reach of science, the authors come from around the globe. I trust that this is in keeping with George's uplifting words on the role of science in our common humanity which I quote from his article in 1997 in the Annual Mechanics Review volume 50, R11-R20:

Through having common objectives and principles by which new knowledge is assessed and disseminated, scientists concerned with a particular field like fluid mechanics form an international community of great unity and moral strength. I believe that the understanding, trust, and goodwill between members of this scientific community transcends geographical and political boundaries and constitutes one of the most important forces for international harmony and friendship in the world today.

Paul Linden 